\title{
Determination of PCDD/F Levels in Wood Shavings Used as Bedding Material for Poultry Production
}

\author{
Miguel Cardo¹, Américo Martins ${ }^{2}$, Carla Raminhos², Maria Campos², Fernando Bernardo \\ ${ }^{1}$ Faculty of Veterinary Medicine (FMV), University of Lisbon, Lisbon, Portugal \\ ${ }^{2}$ Autoridade de Segurança Alimentar e Económica, Laboratório de Físico-Química (LFQ), Lisbon, Portugal \\ Email: m.o.cardo@mail.telepac.pt
}

How to cite this paper: Cardo, M., Martins, A., Raminhos, C., Campos, M. and Bernardo, F. (2016) Determination of PCDD/F Levels in Wood Shavings Used as Bedding Material for Poultry Production. Journal of Environmental Protection, 7, 2047-2055.

http://dx.doi.org/10.4236/jep.2016.713159

Received: October 20, 2016

Accepted: December 17, 2016

Published: December 20, 2016

Copyright $\odot 2016$ by authors and Scientific Research Publishing Inc. This work is licensed under the Creative Commons Attribution International License (CC BY 4.0).

http://creativecommons.org/licenses/by/4.0/ (c) (i) Open Access

\begin{abstract}
During 2006 and 2011, following the implementation of dioxin contamination monitoring in poultry meat, levels higher than legally allowed in meat from poultry slaughtered for human consumption, were found. The wood shavings used as bedding material in the poultry farm showed considerable high contaminations, indicating that these materials were the likely source of contamination of the animals. Wood shavings samples $(n=23)$, used as poultry litters in intensive farms of broilers, were analysed. In both episodes, contamination profiles of higher and lower concentrations, seem to be very similar, being OCDD, OCDF, 1,2,3,4,6,7,8-HpCDD and $1,2,3,4,6,7,8$-HpCDF responsible for $97.4 \%$ of the total contamination. The present work describes the analytical adapted, used methodology and the specific clean-up procedures, which revealed that recoveries of ${ }^{13} \mathrm{C}_{12}$-Labelled compounds added to the wood shavings samples ranged from $71.3 \%$ to $86.3 \%$.
\end{abstract}

\section{Keywords}

Dioxins, Wood Shavings, Analytical Method, Food Chain

\section{Introduction}

Safety of the food chain is periodically challenged due to the occurrence of PCDD, $\mathrm{PCDF}$ and PCBs contamination in food.

Some recent cases of contamination of the food chain are known. An accident occurred in Belgium in 1999 with a tanker carrying frying oil for refining and incorporation in feed which mixed with the container of coolant fluid containing dioxins. The oil ended up being used inadvertently and caused contamination of meat from different 
animals in various countries where the feed was marketed [1].

In Ireland, in December 2008, following samples taken from a pig slaughterhouse in the national residue monitoring plan, results found РСB levels above the limit laid down in Regulation (EC) No. 1881/2006 of the Commission of 19 December 2006 [2]. The animal source of contamination found was feed from a waste recycling facility.

During 2006 and 2011, in Portugal, following the implementation of a National Residues Monitoring Plan, the competent authority found residues of dioxin contamination in poultry meat with levels higher than legally allowed in meat from poultry slaughtered for human consumption.

To identify the original source of contamination of these birds, all potential sources of contamination were analysed and the results showed considerable high contaminations of the wood shavings used as bedding material in the poultry farm, indicating that these materials were the likely source of contamination of the animals [3].

However, the absence of a well established laboratorial methodology applied to that specific matrix (wood shavings) led to the need to adapt the method 1613b [4].

In this paper, it is described the method applied for the determination of PCDD/Fs in this type of matrix and is also done the interpretation of the results, particularly in what regards the source of contamination.

\section{Materials and Methods}

\subsection{Sampling}

Sapling procedures, packing, transport and storage were performed by officers from the competent authority, under the scope of the National Residue Monitoring Plan, respecting the official procedures to ensure stability of conditions and integrity of the sample, to avoid causing any change that could affect the level of dioxins. Each sample was individually packed and labelled in opaque polyethylene sample bags, immediately after sampling. Samples of litter were preserved in dry, cool places.

\subsection{Materials}

All chemicals used were residue analysis Pico grade. Native and carbon-13 labelled PCDD and PCDF standards were obtained from Cerilliant, CIL Cambridge Isotope Laboratories (LGC, Barcelona, Spain) and from Wellington Laboratories (Technospec, Barcelona, Spain). Carbosphere activated carbon, 80 - 100 mesh, with a surface area of $1000 \mathrm{~m}^{2} / \mathrm{g}$ was obtained from Altech (I.L.C., Lisbon). The alumina Basic Super I for dioxin analysis was purchased from ICN (Promochem, Barcelona, Spain).

\subsection{Extraction Procedure}

The samples of wood shavings were grinded and homogenised, then mixed with sodium sulphate and transferred to a Twisselman extractor. Prior to extraction, samples were fortified with a standard mixture containing ${ }^{13} \mathrm{C}_{12}$-labeled PCDDs and PCDFs and equilibrated during at least one hour. After that time, a 24 hours' extraction was per- 
formed using hexane/dichloromethane mixture $(50: 50 \mathrm{v} / \mathrm{v})$. The extracts were evaporated to dryness.

\subsection{Carbon Chromatography}

For carbon chromatography was used glass columns with $2 \mathrm{~g}$ of Carbosphere. The sample residue was dissolved in dichloromethane and brought onto the top of the Carbosphere column which was placed in a reflux unit and refluxed for $2 \mathrm{~h}$ with dichloromethane. This fraction was discarded. The column was rinsed with toluene and refluxed for $1 \mathrm{~h}$ with toluene, which was discarded. The PCDD/F fraction was recovered by reverse elution from the column by refluxing with toluene for $24 \mathrm{~h}$. This fraction was carefully evaporated to dryness under a gentle stream of nitrogen.

\subsection{Alumina Chromatography}

The residue was solved in hexane and the mixture was brought onto a column containing acidic silica gel and $5 \mathrm{~g}$ alumina, previous washed with hexane. The alumina column was eluted with a mixture of hexane/DCM $(97: 3 \mathrm{v} / \mathrm{v})$. This eluate was discarded. The PCDDs/PCDFs were eluted using a hexane/DCM mixture (60:40 v/v).

\subsection{Silica Chromatography}

The residue was solved in hexane and the sample was brought onto a column containing neutral silica, basic silica and two acid silica layers at different concentrations ( $44 \%$ and $22 \%)$. The eluate was evaporated to dryness in Kuderna-Danish concentrators (KD) under a nitrogen blowdown device to be injected in the GC/HRMS.

\subsection{Instrumental Analysis}

All analyses were performed by GC-HRMS using a MAT95XL high-resolution mass spectrometer (Finnigan, Bremen, Germany) coupled to Trace GC 2000 gas chromatograph (Thermo Finnigan, Bremen, Germany) equipped with an AS2000 auto-sampler. Gas chromatographic separations were carried out using a DB-5 MS capillary column $(60 \mathrm{~m} \times 0.25 \mathrm{~mm}$ i.d from J\&W Scientific, USA) using helium as carrier gas, with a constant flow at $1 \mathrm{~mL} / \mathrm{min}$.

The samples and standards were injected $(2 \mu \mathrm{L})$ in split less mode (split less time 1 min) at an injector temperature of $280^{\circ} \mathrm{C}$ and at an initial oven temperature of $120^{\circ} \mathrm{C}$. After $1 \mathrm{~min}$, the temperature was ramped at $25^{\circ} \mathrm{C} / \mathrm{min}$ to $200^{\circ} \mathrm{C}$ and then at $3^{\circ} \mathrm{C} / \mathrm{min}$ up to $300^{\circ} \mathrm{C}$. The latter temperature was held during $11 \mathrm{~min}$.

The mass spectrometer was operated in the electron impact ionization mode using selected ion monitoring (SIM). Electron energy was set to $40 \mathrm{eV}$ and the source temperature was set at $250^{\circ} \mathrm{C}$. The MS system was tuned to a resolution of 10,000 (10\% valley) and masses issued from FC-43 (Perfluorotributylamine) tuning compound were used as lock mass. In order to establish the calibration curve for each congener, a set of calibration solutions were injected in every sequence of injection series.

The two most abundant signals of the molecular ion cluster were recorded (from 
tetra-to octa-chlorodibenzo-p-dioxins and -dibenzofurans). Quantification was performed using internal standards and the isotopic dilution technique. The isotopic ratio between principal and secondary signals, for each congener, was verified using the criteria of $\pm 15 \%$ of the theoretical value. For calculation of the detection limits, a signal-to-noise ratio of 3:1 was applied.

\subsection{Quality Control}

Every batch of samples has a procedure blank control and all samples were spike with ${ }^{13} \mathrm{C}_{12}$-labelled reference compounds. Results were corrected with recovery rate.

\subsection{Statistical Analysis}

Analysis of data was carried out in accordance with the methodology of the USA EPA for analysis of contaminants [5]. This procedure includes the conversion of the congeners concentration into a decimal percentage of the sum of congeners, the con- struction of the bar plot of the standard concentrations and the use of the square of the Pearson correlation coefficient (r2) [6] as a measure to assess whether the profile of the concentration of congeners in the samples (compared visually on the bar plot) is statistically similar. It is considered that the profiles are similar if the average of $r^{2}$ is close to 1 and the standard deviation (SD) is next to zero.

\section{Results}

The assessed data from the wood shaving analysis concerns 23 samples are presented in Table 1.

At that time, the highest levels of dioxins found in the most contaminated wood shavings samples ( $\geq 2 \mathrm{pg}$ PCDD/F-WHO-TEQ/g) were $368 \mathrm{pg}$ PCDD/F-WHO-TEQ/g with an average of $154 \mathrm{pg}$ PCDD/F-WHO-TEQ/g in 2006 and $446 \mathrm{pg}$ PCDD/F-WHOTEQ/g with an average of $169 \mathrm{pg}$ WHO-TEQ/g in 2011.

The contamination profile shows that the total contamination was predominantly constituted by the most chlorinated congeners (97.4\%), having OCDD 73.5\%, OCDF 8.2\%, 1,2,3,4,6,7,8-HpCDD 13\% and 1,2,3,4,6,7,8-HpCDF 2.7\% (Figure 1).

The square of the Pearson correlation coefficient $\left(\mathrm{r}^{2}\right)$ and standard deviation (sd) of the different congeners relative concentrations found in the wood shavings analysis, is considerable $\left(r^{2}=0.98\right.$ and $\left.s d=0.02\right)$.

Table 1. Results of PCDD/F-WHO-TEQ/g found in wood shavings (pg/g)

\begin{tabular}{|c|c|c|c|c|c|c|c|}
\hline Incident & $\begin{array}{c}\text { Total } \\
\text { Number of } \\
\text { Samples (n) }\end{array}$ & $\begin{array}{c}\text { Number of Samples } \\
\text { with Conc. } \\
\text { ( } \geq 2 \text { pg } \\
\text { PCDD/F-WHO- } \\
\text { TEQ/g) }\end{array}$ & $\begin{array}{c}\text { Number of } \\
\text { Samples with } \\
\text { Conc. }(<2 \mathrm{pg} \\
\text { PCDD/F-WHO- } \\
\text { TEQ/g) }\end{array}$ & $\begin{array}{c}\text { Highest } \\
\text { concentration } \\
\text { (pg PCDD/F-WHO- } \\
\text { TEQ/g) }\end{array}$ & $\begin{array}{c}\text { Average } \\
\text { concentration } \\
\text { (pg } \\
\text { PCDD/F-WHO- } \\
\text { TEQ/g) (SD) }\end{array}$ & $\begin{array}{c}\text { Average } \\
\text { concentration } \\
(\geq 2 \text { pg } \\
\text { PCDD/F-WHO- } \\
\text { TEQ/g) (SD) }\end{array}$ & $\begin{array}{c}\text { Average } \\
\text { concentration } \\
(<2 \text { pg } \\
\text { PCDD/F-WHO- } \\
\text { TEQ/g) (SD) }\end{array}$ \\
\hline 2006 & 10 & 4 & 6 & 368 & $62(116)$ & $154(148)$ & $0.47(0.35)$ \\
\hline 2011 & 13 & 6 & 7 & 446 & $78(164)$ & $169(216)$ & $0.42(0.62)$ \\
\hline
\end{tabular}




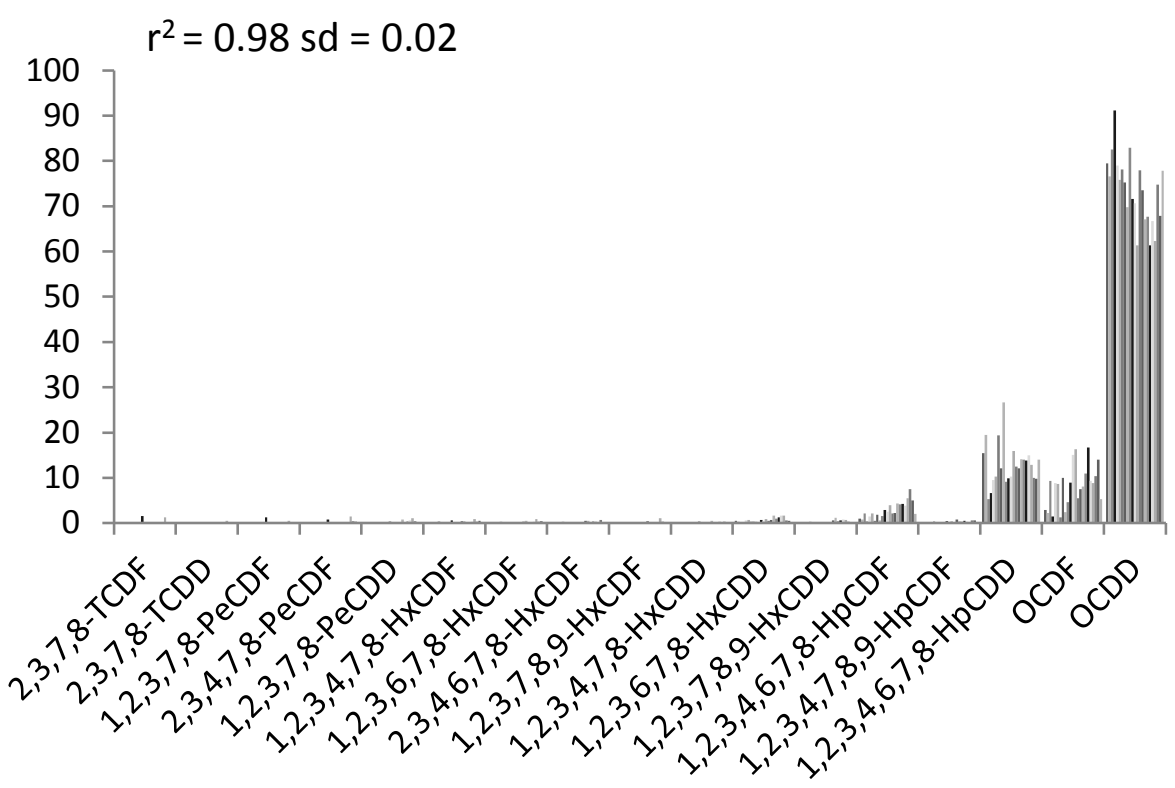

Figure 1. Relative concentration of the different congeners in all wood shavings samples (contamination profile).

Recoveries of ${ }^{13} \mathrm{C}_{12}$-Labelled compounds added to the wood shavings samples ranged from $71.3 \%$ and $86.3 \%$ (Table 2).

\section{Discussion}

\section{Main differences between used method and USEPA method 1613B}

The main steps that have been modified and adapted in the method used for the analysis of wood shavings are resumed in Figure 2, comparatively with the USEPA method 1613B.

The analytical procedure used to quantify PCDD/F on the wood shavings samples in this study was based on the USEPA method 1613B with the follow modifications:

\section{Extraction}

The reflux was done in one step for a period of 24 hours with hexane/dichloromethane mixture (50: $50 \mathrm{v} / \mathrm{v}$ ) and not the two steps foreseen in the reference method with toluene.

\section{Concentration}

The extracts were concentrated using a rotary evaporator with a recirculating water pump and adapting vacuum to the system, taking care with the speed of evaporation because if it is too fast, part of the analyte may be lost.

The concentration was performed in two steps, warming the water bath and applying different pressures, 550 mbar to evaporate the DCM and 250 mbar to evaporate the n-hexane.

\section{Extract clean-up (Carbon column)}

A carbon column clean-up was used to remove nonpolar interferences.

Unlike the reference method, the back extract was not performed after the concen- 
Table 2. Recovery rates (R) and Level of Quantification (LQ) by each PCDD/PCDF congener.

\begin{tabular}{ccccccc}
\hline & $\mathrm{R}(\%)$ & $\mathrm{S}_{\mathrm{R}}(\%)$ & $\mathrm{R}-2^{*} \mathrm{~S}_{\mathrm{R}}(\%)$ & $\mathrm{R}+2^{*} \mathrm{~S}_{\mathrm{R}}(\%)$ & Average LQ SD LQ (pg/g) \\
\hline $2378-\mathrm{TCDF}$ & 79.3 & 15.0 & 49.3 & 109.3 & 0.019 & 0.02 \\
$2378-\mathrm{TCDD}$ & 84.7 & 13.1 & 58.5 & 110.8 & 0.013 & 0.02 \\
$12378-\mathrm{PeCDF}$ & 85.0 & 12.1 & 60.8 & 109.2 & 0.028 & 0.04 \\
$23478-\mathrm{PeCDF}$ & 84.0 & 13.0 & 58.1 & 109.9 & 0.028 & 0.04 \\
$12378-\mathrm{PeCDD}$ & 86.3 & 11.5 & 63.4 & 109.2 & 0.04 & 0.05 \\
$123478-\mathrm{HxCDF}$ & 85.2 & 12.8 & 59.7 & 110.8 & 0.041 & 0.06 \\
$123678-\mathrm{HxCDF}$ & 79.9 & 12.8 & 54.4 & 105.5 & 0.041 & 0.06 \\
$234678-\mathrm{HxCDF}$ & 80.9 & 13.3 & 54.3 & 107.5 & 0,043 & 0.07 \\
$123789-\mathrm{HxCDF}$ & 84.3 & 13.9 & 56.5 & 112.2 & 0,043 & 0.09 \\
$123478-\mathrm{HxCDD}$ & 85.6 & 11.2 & 63.1 & 108.0 & 0,059 & 0.08 \\
$123678-\mathrm{HxCDD}$ & 81.5 & 11.2 & 59.0 & 104.0 & 0,05 & 0.07 \\
$123789-\mathrm{HxCDD}$ & 81.5 & 11.2 & 59.0 & 104.0 & 0.05 & 0.08 \\
$1234678-\mathrm{HpCDF}$ & 79.3 & 11.2 & 56.9 & 101.8 & 0.056 & 0.06 \\
$1234789-\mathrm{HpCDF}$ & 84.1 & 12.9 & 58.4 & 109.9 & 0.071 & 0.09 \\
$1234678-\mathrm{HpCDD}$ & 83.2 & 12.0 & 59.3 & 107.1 & 0.09 & 0.13 \\
OCDF & 71.3 & 14.3 & 42.8 & 99.9 & 0.09 & 0.14 \\
OCDD & 71.3 & 14.3 & 42.8 & 99.9 & 0.15 & 0.33 \\
\hline
\end{tabular}

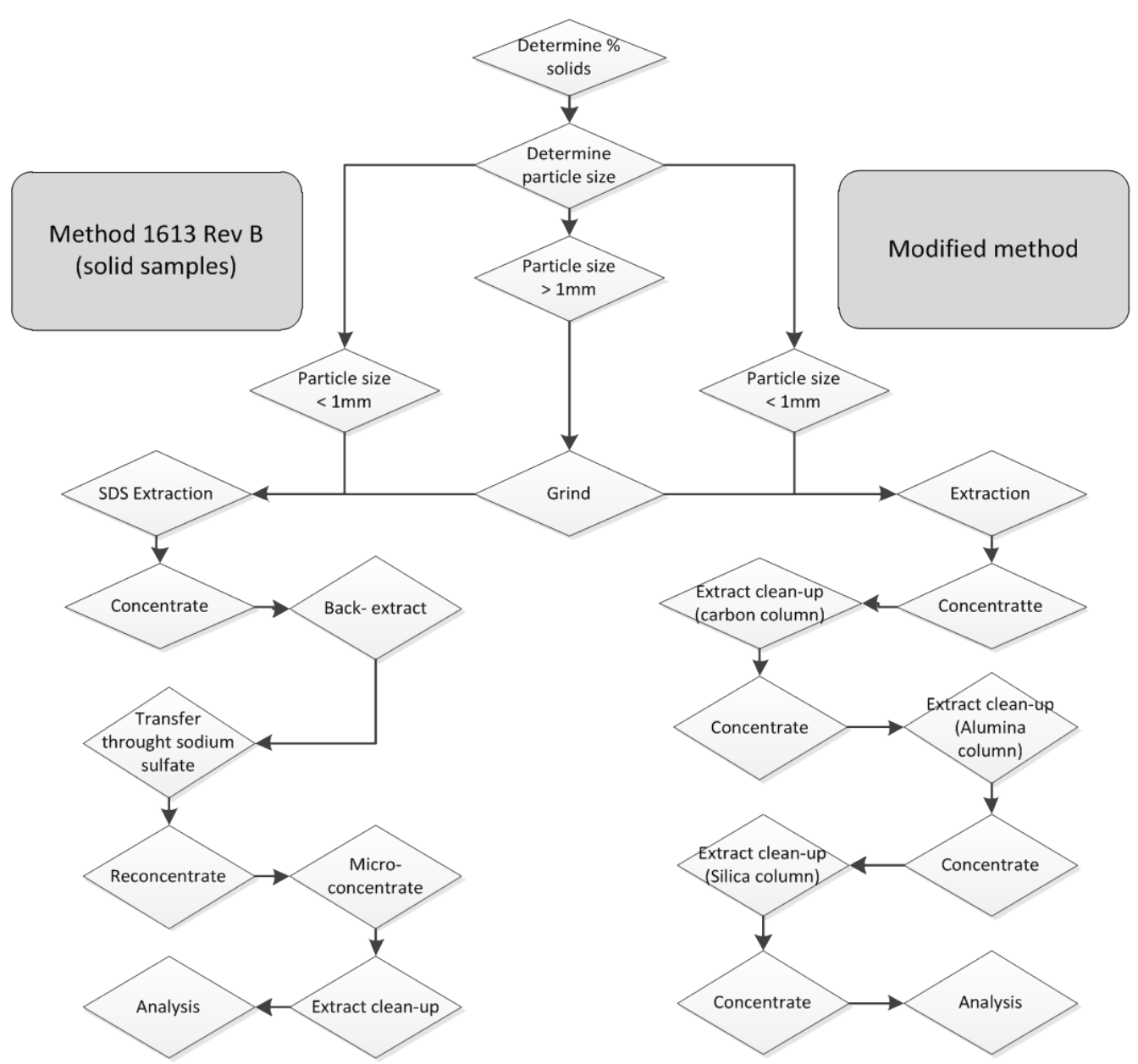

Figure 2. Flow chart of the USEPA method 1613B and the used method. 
tration. Instead, the concentrated extract was cleaned-up in a carbon column succeeded by a back flash reflux.

In the adapted method, the column was just pre-eluted with $10 \mathrm{ml}$ of DCM which were discarded. The reference method foresees a pre-elution of the column with $5 \mathrm{ml}$ of toluene followed by $2 \mathrm{~mL}$ of methylene chloride: methanol: toluene $(15: 4: 1 \mathrm{v} / \mathrm{v}), 1 \mathrm{~mL}$ of DCM: cyclohexane $(1: 1 \mathrm{v} / \mathrm{v})$, and $5 \mathrm{~mL}$ of hexane.

The sample extract was added to the column, the sample container was rinsed twice with $5 \mathrm{~mL}$ portions of DCM applied separately to the column whilst the reference method foresees the same procedure with $1 \mathrm{~mL}$ portions of hexane and a final addition of $2 \mathrm{~mL}$ of hexane to complete the transfer.

After the addition of the sample, a two hours reflux with $35 \mathrm{~mL}$ of DCM was completed and when finished, the carbon columns were washed with $15 \mathrm{ml}$ toluene to drag the excess of DCM, succeeded by a new one-hour reflux of $35 \mathrm{~mL}$ of toluene. The reference method foresees an elution with two $3 \mathrm{~mL}$ portions of hexane, $2 \mathrm{~mL}$ of methylene chloride: cyclohexane $(1: 1 \mathrm{v} / \mathrm{v})$ and $2 \mathrm{~mL}$ methylene chloride: methanol: toluene $(15: 4: 1 \mathrm{v} / \mathrm{v})$.

The column was inverted (back flash), and eluted the PCDDs/PCDFs with $45 \mathrm{~mL}$ of toluene during a 24-hour reflux period, whilst the reference method foresees an elution with $20 \mathrm{~mL}$ of toluene.

\section{Extract clean-up (Alumina column)}

The alumina column was used to remove nonpolar and polar interferences as well as chlorodiphenyl ethers.

The reference method prescribes either the use of acid alumina (6 $\mathrm{g}$ acid alumina) or the use of basic alumina ( $6 \mathrm{~g}$ basic alumina). In the methodology used in this study, the column was packed with $5 \mathrm{~g}$ of basic Alumina (Alumina B-Super 1 for dioxin analysis).

The pre-elution of the column followed the reference method.

The concentrated extract solution was diluted in $5 \mathrm{ml}$ hexane and added to the column (no dilution on the reference method). The receiver was rinsed twice, with $2.5 \mathrm{ml}$ portions of hexane ( $1 \mathrm{ml}$ in the reference method) and applies separately to the column. The interfering compounds were eluted with $20 \mathrm{ml}$ hexane: DCM (97:3 v/v) $(100 \mathrm{ml}$ hexane in the reference method) and the eluate was discarded.

In this methodology, the last elution was completed with $80 \mathrm{ml}$ of a DCM: hexane solution $(40: 60 \mathrm{v} / \mathrm{v})$ to obtain the final extract which was collected. According to the reference method, the choice of eluting solvents would depend on the choice of alumina (acid or basic), $20 \mathrm{~mL}$ DCM: hexane $(20: 80 \mathrm{v} / \mathrm{v})$ when acid alumina is used or 20 $\mathrm{mL}$ DCM: hexane (50:50 v/v) when basic alumina is used.

\section{Extract clean-up (Silica gel column)}

The extract was concentrated and eluted, after an elution of 1 to $3 \mathrm{ml}$ of hexane (50$100 \mathrm{~mL}$ hexane in the reference method) through a column of silica filled in the following sequence (glass wool plug into the tapered end of a graduated serological pipet, pack with $1 \mathrm{~cm}$ neutral silica, $1 \mathrm{~cm}$ basic silica $(\mathrm{NaOH}), 1 \mathrm{~cm}$ acid silica at $44 \%$ topped with $1 \mathrm{~cm}$ acid silica at $22 \%$ and a glass wool plug). 
The reference method foresees a different composition of the column which is packed bottom to top with: $1 \mathrm{~g}$ silica gel, $4 \mathrm{~g}$ basic silica gel, $1 \mathrm{~g}$ silica gel, $8 \mathrm{~g}$ acid silica gel, $2 \mathrm{~g}$ silica gel and $4 \mathrm{~g}$ granular anhydrous sodium sulphate taped with glass-wool.

The concentration flask was rinsed twice with $2 \mathrm{ml}$ of hexane $(1 \mathrm{~mL}$ of hexane in the reference method with an extra elution of $100 \mathrm{~mL}$ hexane through the column).

The product of this elution was concentrated and placed in a Kuderna-Danish concentrator (KD) previously prepared with ebullition regulators for injection in the GC/ HRMS.

\section{Level of contamination and congener's profile}

The results revealed average levels of $62 \mathrm{pg}$ PCDD/F-WHO-TEQ/g fat in 2006 and of $78 \mathrm{pg}$ PCDD/F-WHO-TEQ/g fat in 2011, which exceeded the maximum limit allowed by the European legislation for these substances in poultry meat, set at 2 pg PCDD/ F-WHO-TEQ/g fat until 2011.

Once applied the statistical methodology, it becomes clear that in both incidents the contamination profiles were very similar (Figure 1).

Risk management concerning the presence of environmental contaminants that may reach the food chain is a challenging task and must always put in perspective some unusual sources of contamination.

In both incidents during 2006 and 2011, the association between the poultry meat contamination and the litters used in the poultry production was established.

The pattern detected in the wood shavings contamination matches the profile found for contaminated technical pentachlorophenol by other authors [7] [8] [9]. This could suggest that the wood shavings used in the litters were obtained from treated wood, being the wood preservative the possible source (inadequate disposal of wood by-products).

The role of metal catalysts in de novo formation of PCDD/PCDF is described by Nigel W. Tame et al. [10] and cooper is described as having the ability to couple with oxygen, lowering the temperature of exothermic oxidation with chlorination of the carbon. The high chlorination efficiency manifests in the homologues profiles where octa and hepta homologues of dibenzofuran and dibenzo-p-dioxin dominate. Cooper is very often used in commercial industry wood preservative solutions.

Recoveries of 13C12-Labelled compounds added to the wood shavings samples of the modified method are considered as acceptable by the European legislation. The recovery shall be within $60 \%$ to $120 \%$ especially for congeners contributing more than $10 \%$ to the TEQ-level for analysis of foodstuffs and feed for confirmatory methods and, for screening methods, the recoveries shall be in the range of $30 \%$ to $140 \%$ [11] [12].

\section{Conclusions}

In both incidents during 2006 and 2011, contamination profiles of the wood shavings from the poultry litters seem to be very similar $\left(r^{2}=0.98\right.$ and $\left.s d=0.02\right)$, being OCDD, OCDF, $1,2,3,4,6,7,8-\mathrm{HpCDD}$ and $1,2,3,4,6,7,8$-HpCDF responsible for $97.4 \%$ of the total contamination.

The method used, with all adaptations described, proved to be accurate and reproducible in the determination of low and high levels of PCDD/PCDF in wood shavings 
used as litters in poultry production farms. Quality requirements of the reference standards for recoveries, for food and environmental dioxins analysis are met.

Further investigation is still needed to explain the formation of PCDD/F in order to clarify the possible role of wood preservatives in the contamination of the poultry food production chain.

\section{References}

[1] Bernard, A., Broeckaert, F., Poorter, G., Cock, A., Hermans, C., Saegerman, C.E. and Houins, G. (2002) The Belgian PCB/Dioxin Incident: Analysis of the Food Chain Contamination and Health Risk Evaluation. Brussels, Belgium. Environmental Research, 88, 1-18. https://doi.org/10.1006/enrs.2001.4274

[2] The Commission of the European Communities (2006) Commission Regulation (EC) No 1881/2006 of 19 December 2006, Setting Maximum Levels for Certain Contaminants in Foodstuffs. Official Journal of the European Union, L364, 5-24.

[3] Cardo, M.O., Castel-Branco, M., Andreozzi, V. and Bernardo, F.A. (2014) Dioxins in the Food Chain: Contamination Fingerprint Analysis in Breeding Hens, Hatching Eggs and Broilers. Journal of Environmental Protection, 5, 1323-1330.

https://doi.org/10.4236/jep.2014.513126

[4] United States Environment Protection Agency (1994) Method 1613 Revision B-TetraThrough Octa-Chlorinated Dioxins and Furans by Isotope Dilution HRGC/HRMS. United States Environment Protection Agency, Washington DC, 89.

[5] Russell, H. and Plumb, J. (2004) Fingerprint Analysis of Contaminant Data: A Forensic Tool for Evaluating Environmental Contamination. National Exposure Research Laboratory Environmental Sciences Division, Las Vegas, 27.

[6] Johnson, R. and Wichern, D. (2001) Applied Multivariate Statistical Analysis. 5th Edition, Prentice Hall, Upper Saddle River, 761.

[7] Hagenmaier, H. and Brunner, H. (1987) Isomer Specific Analysis of Pentachlorophenol and Sodium Pentachlorophenate for 2,3,7,8-Substituted PCDD and PCDF at Sub-PPB Levels. Chemosphere, 16, 1759-1764. https://doi.org/10.1016/0045-6535(87)90164-0

[8] Fries, G.F., Feil, V. and Davison, K. (1996) The Significance of Pentachlorophenol-Treated Wood as a Source of Dioxin Residues in United States Beef. Organohalogen Compounds, 28, 156-159.

[9] Cleverly, D., Schaum, J., Schweer, G., Becker, J. and Winters, D. (1997) The Congener Profiles of Anthropogenic Sources of Chlorinated Dibenzo-p-Dioxins and Chlorinated Dibenzofurans in the United States. The 17 th International Symposium on Chlorinated Dioxins and Related Compounds, Indianapolis, 25-29 August 1997, 430-435.

[10] Tame, N.W., Dlugogorski, B.Z. and Kennedy, E.M. (2007) Formation of Dioxins and Furans during Combustion of Treated Wood. Progress in Energy and Combustion Science, 33, 384-408. https://doi.org/10.1016/j.pecs.2007.01.001

[11] European Commission (2014) Commission Regulation (EU) No 589/2014 of 2 June 2014, Laying down Methods of Sampling and Analysis for the Control of Levels of Dioxins, Dioxin-Like PCBs and Non-Dioxin-Like PCBs in Certain Foodstuffs and Repealing Regulation (EU) No 252/2012. pp. 23.

[12] European Commission (2014) Commission Regulation (EU) No 709/2014 of 20 June 2014 Amending Regulation (EC) No 152/2009 as Regards the Determination of the Levels of Dioxins and Polychlorinated Biphenyls. pp. 18. 
Submit or recommend next manuscript to SCIRP and we will provide best service for you:

Accepting pre-submission inquiries through Email, Facebook, LinkedIn, Twitter, etc. A wide selection of journals (inclusive of 9 subjects, more than 200 journals)

Providing 24-hour high-quality service

User-friendly online submission system

Fair and swift peer-review system

Efficient typesetting and proofreading procedure

Display of the result of downloads and visits, as well as the number of cited articles

Maximum dissemination of your research work

Submit your manuscript at: http://papersubmission.scirp.org/

Or contact jep@scirp.org 